\title{
VULNERABILIDADE AMBIENTAL E SOCIAL: ESTUDO DE CASO EM UM BAIRRO NO MUNICÍPIO DE SALES-SP
}

\author{
C. A. F. Silva', G. Malafaia ${ }^{2}$, B. G. A. Veiga ${ }^{3}$, A. L. A. Castro ${ }^{4}$ \\ ${ }^{1}$ Pós-Graduanda (Lato sensu) em Ciência Política pela Faceres - clelia@gmail.com \\ ${ }^{2}$ Laboratório de Biologia Geral - Instituto Federal Goiano - guilhermeifgoiano@gmail.com \\ ${ }^{3}$ Reitoria - Instituto Federal Goiano - Câmpus Urutaí - brunoadaveiga@gmail.com \\ ${ }^{4}$ Laboratório de Zoologia - Instituto Federal Goiano - Câmpus Urutaí - andrelscastro@gmail.com
}

Artigo submetido em março/2012 e aceito em setembro/2012

\section{RESUMO}

O presente estudo objetivou retratar a real condição socioambiental da população de um bairro do município de Sales-SP. A pesquisa, realizada através de um inquérito domiciliar (com aplicação de um questionário) e de observação direta dos pesquisadores, avaliou a exposição dos indivíduos às agressões ambientais e os efeitos adversos à saúde "física" e "social" dessas agressões. Além disso, buscou-se identificar as percepções dos moradores frente a essas agressões e opiniões relacionadas à questão ambiental. Os resultados obtidos denunciam condições de vulnerabilidade vivenciada pelas famílias que sofrem com a precariedade e insalubridade das suas moradias. Além disso, evidenciaram-se situações de descaso do poder público, bem como retratou-se pouca participação comunitária na identificação de problemas ambientais locais e na preservação do meio ambiente. Conclui-se que há necessidade que intervenções ligadas à melhoria da qualidade de vida da população residente no bairro estudado sejam realizadas, com destaque para ações de saneamento básico e educação ambiental. Numa instância mais genérica, o presente estudo suscita discussões sobre a importância da verificação e dos indicadores que fornecem a avaliação da qualidade ambiental em áreas urbanizadas, utilizando estes como um alicerce para o planejamento das cidades e imprescindível para melhorar a qualidade de vida nas cidades.

PALAVRAS-CHAVE: qualidade ambiental, meio ambiente urbano, qualidade de vida, saneamento ambiental.

\section{ENVIRONMENTAL AND SOCIAL VULNERABILITY: A CASE STUDY IN SALES-SP}

\begin{abstract}
This study aimed to portray the real social and environmental condition of the population from SalesSP. The survey, conducted through a household survey (with application of the questionnaire) and direct observation of the researchers, evaluated the exposure of individuals to environmental insults and adverse health effects "physics" and "social" these aggressions. In addition, we sought to identify the perceptions of residents about these aggressions and opinions related to environmental issues. The results expose conditions of vulnerability experienced by families who suffer from job insecurity and unhealthy conditions of their dwellings. In addition, situations become apparent
\end{abstract}

indifference of the public and identifies little community participation in identifying local environmental problems and preserving the environment. We conclude that there is a need that interventions related to improving the quality of life of people living in this neighborhood are performed, with emphasis on basic sanitation and environmental education. In a more general instance, this study raises discussions about the importance of checking and indicators that provide an assessment of environmental quality in urban areas, using these as a foundation for the planning of cities and essential to improve the quality of life in cities.

KEY-WORDS: environmental quality, urban environment, quality of life, environmental sanitation. 


\section{VULNERABILIDADE AMBIENTAL E SOCIAL: ESTUDO DE CASO EM UM BAIRRO NO MUNICÍPIO DE SALES-SP}

\section{INTRODUÇÃO}

Durante as últimas décadas tem havido aumento das discussões acerca dos problemas ambientais provocados por atividades antrópicas e as suas consequências em nível local, regional, nacional e mundial. Estudos têm demonstrado que os espaços urbanos, em especial, têm provocado impactos ambientais de grande magnitude em virtude de ações antropogênicas (Mendonça, 2002; Giatti et al., 2004; Buccheri-Filho, 2006; Firmino et al., 2011).Contudo, do ponto de vista histórico, percebe-se que com o desenvolvimento capitalista o processo de industrialização e urbanização no Brasil, consolidado nas últimas décadas, trouxe para muitas regiões, além dos impactos ambientais, a ampliação das carências sociais e dos serviços públicos, bem como o estrangulamento da infra-estrutura das cidades, especialmente nos setores de saneamento e habitação (Günther, 2005).

Os projetos de desenvolvimento de muitas cidades não produziram os benefícios previstos nas condições de vida das pessoas, ou seja, acabaram contribuindo para a exclusão social, reduzindo a qualidade de vida de parte das populações. Para Natal et al. (2005), é notável o agravamento das contradições sociais em que o desemprego, o subemprego, o emprego informal, o aumento da marginalidade e da violência somam-se às já precárias condições de sobrevivência da população, sobretudo, aquela abrigada inadequadamente em favelas e periferias.

Do ponto de vista de saúde pública, tem-se que a falta ou precárias condições dos serviços de saneamento básico podem ocasionar o aumento da incidência e prevalência de várias doenças, o incremento dos gastos públicos relativos ao tratamento de doentes, a baixa qualidade de vida da população, bem como a diminuição da sua expectativa de vida (Philippi-Jr \& Malheiros, 2005).

Somam-se ainda como problemas socioambientais o fato de no Brasil persistir uma demanda populacional não atendida por serviços adequados de saneamento básico, atingindo de forma mais severa a população de baixa renda, concentrada nos pequenos municípios e nas periferias dos grandes centros urbanos e regiões metropolitanas. Aliado a isso, tem-se o problema da geração e do mau gerenciamento dos resíduos urbanos. Conforme discutido por Philippi-Jr \& Aguiar (2005), o tratamento e a destinação desses resíduos constituem um serviço de saneamento básico de alto interesse para a saúde pública. Apesar da existência de diversas formas de destinar resíduos humanos, na maioria das cidades os destinos mais comuns são os lixões, onde o lixo é depositado deliberadamente a céu aberto e não recebe nenhuma forma de tratamento.

Estudos envolvendo diferentes tipos de pesquisas têm demonstrado que a destinação incorreta do lixo gera diversos problemas sociais, econômicos e ambientais (Vieira, 2002; Rodrigues et al., 2010). Agravando esse cenário, surgem os novos atores sociais recolhendo lixo reciclável como fonte de sobrevivência. Mais que um problema ambiental, a questão do lixo tornou-se também um problema social e político, pois abriga milhares de pessoas no trabalho informal de forma cruel e excludente. Muitas famílias encontram neles o seu sustento ao vislumbrarem na atividade uma fonte de renda e até mesmo de alimento. 
Neste contexto, as cidades passaram a se defrontar com uma situação grave que exige intervenções em áreas que extrapolam as tradicionais políticas na área urbana. Trata-se de amplos projetos de infra-estrutura, políticas sociais, programas de emprego e políticas ambientais, envolvendo inclusive estratégias locais de dinamização das atividades econômicas. Para enfrentar tais problemas, há a necessidade de intensificar as análises que articulam os aspectos físicos e humanos na avaliação de riscos de fenômenos naturais e sociais, na identificação de populações vulneráveis e no desenvolvimento de procedimentos que eliminem os efeitos dos possíveis danos (Rosa \& Silva, 2012). É preciso ainda compreender e considerar os elementos da vida cotidiana e as lógicas que interagem na dinâmica pública de serviços e infraestrutura, assim como assegurar a participação da comunidade, posto que ela contém informações fundamentais à tomada de decisões.

Nesse contexto, o presente estudo teve por objetivo retratar a real condição socioambiental da população de um bairro do município de Sales-SP. Avaliou-se a exposição dos indivíduos às agressões ambientais e os efeitos adversos à saúde. Acredita-se que este estudo possa contribuir para a institucionalização de políticas públicas locais e, em linhas gerais, pretende-se suscitar discussões sobre a importância da verificação e dos indicadores que fornecem a avaliação da qualidade ambiental em áreas urbanizadas, utilizando estes como um alicerce para o planejamento das cidades e imprescindível para melhorar a qualidade de vida nas cidades.

\section{MÉTODOS E ESTRATÉGIA DE AÇÃO}

\section{Área de estudo}

A presente pesquisa foi desenvolvida em 30 domicílios (o que representou 30 famílias) do bairro São Benedito, município de Sales-SP (Figura 1). O referido município localiza-se no centrooeste paulista, às margens do rio Tietê, distante a $468 \mathrm{Km}$ da capital do estado, pertence à 8a região administrativa de São José do Rio Preto/SP. De acordo com o censo/2010 realizado pelo IBGE a população total do município é de 5.434 habitantes numa área territorial de $308,46 \mathrm{Km}^{2}$ (IBGE, 2010).

O bairro São Benedito encontra-se inserido no limite urbano do município de Sales/SP, especificamente na região norte da cidade. É formado por 15 ruas nas quais não há estabelecimentos públicos, comerciais, industriais e de prestação de serviços. A população do bairro é estimada em 400 habitantes. Tem ao norte limite com a vicinal Tenente José Nassif, ao sul com o bairro Jardim Planalto, a leste com o bairro Jardim Moraes e a oeste com o rio Capoeirinha. É uma área de alta densidade de ocupação, classificada como urbanização inadequada em função da degradação ambiental com impacto na formação da vida coletiva e social.

O bairro em questão foi escolhido por apresentar um grupo populacional vivendo em situação de risco e vulnerabilidade social devido aos altos índices de salubridade ambiental. 0 local é caracterizado pela existência de graves problemas sociais, ambientais, desemprego, instabilidade profissional, além de evasão e baixa assiduidade escolar. 


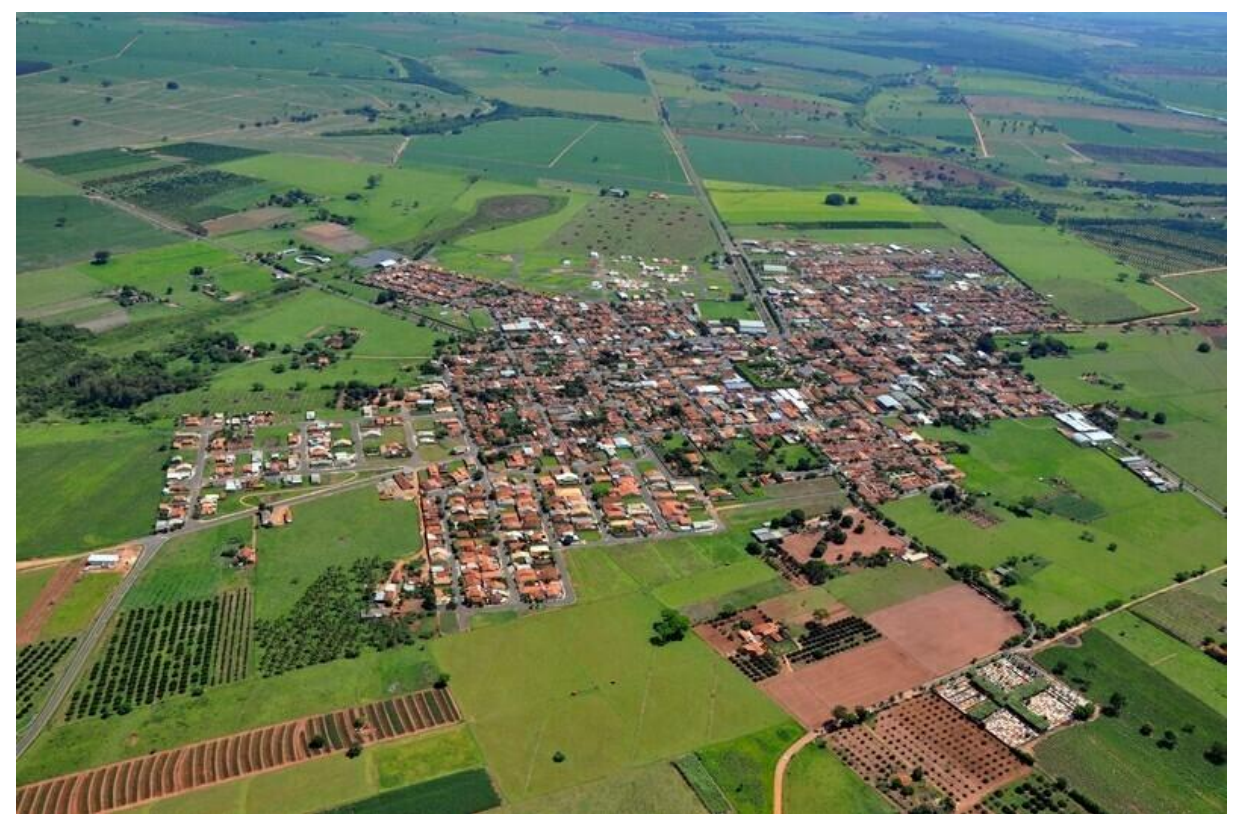

Figura 1 - Vista aérea da cidade de Sales, SP. Fonte: Fonte: Prefeitura Municipal de Sales (2012).

Conforme Amêndola (1999), o surgimento do bairro ocorreu mediante a aprovação da Lei 1.066 de 04 de dezembro de 1990 para fins de loteamento. No entanto, os primeiros lotes habitacionais foram doados para pessoas em situação de risco e vulnerabilidade social no município. A maioria das casas do bairro é inacabada, com redes de esgoto inacabadas, ruas com iluminação precária e poucas árvores.

\section{Coleta de dados}

A coleta de dados foi realizada por meio da aplicação de um questionário estruturado, o qual continha questões referentes à origem e tratamento da água para uso humano, destino do esgoto e do lixo, bem como questões socioeconômicas e de saúde. Para uma melhor amostragem foram visitados dois domicílios por rua (perfazendo um total de 15 ruas), havendo uma distribuição espacial equitativa da amostra ao longo do bairro. A cada domicílio visitado aplicava-se o questionário a um morador responsável, de acordo com sua disponibilidade.

Para a coleta de dados foi utilizada a entrevista estruturada, composta por 20 questões abertas. Os dados relativos à habitação e saneamento foram obtidos mediante informação dos entrevistados associados à observação in locco feita pelo entrevistador.

\section{Questões éticas}

Essa pesquisa foi submetida à apreciação pelo Comitê de Ética em Pesquisa da FACERES sob o protocolo no 003 , tendo sido aprovada em 21/05/2009. Todos os sujeitos foram convidados a participar em caráter voluntário e, os que aceitaram, assinaram um Termo de Consentimento Livre e Esclarecido após receberem as informações sobre o projeto. 


\section{RESULTADOS E DISCUSSÃO}

O perfil genérico dos entrevistados mostrou que os mesmos possuem renda familiar inferior a um salário mínimo e não possuem qualificação profissional. No quesito educacional formal, predominaram nos domicílios os indivíduos que possuem baixos níveis de escolaridade, consolidando ainda mais a exclusão social. A análise aponta que $65 \%$ dos entrevistados não concluíram o Ensino Fundamental, muitos por não frequentarem a escola quando estavam em idade escolar, sobretudo, em função do ingresso precoce no mercado de trabalho, demonstrando a trajetória de vida marcada pelo encurtamento da infância.

A questão do gênero destacou-se neste contexto ao influenciar de forma marcante os modelos de organização e o mundo produtivo, pois em $23,3 \%$ dos domicílios as mulheres são responsáveis pela economia familiar. Esses dados corroboram outros estudos, que mostram as transformações sociais contemporâneas, os novos arranjos familiares e a importância da mulher para o sustento da família atual (Lipovetsky, 2000; Fleck \& Wagner, 2003; Perucchi \& Beirão, 2007). Contudo, a maioria dessas mulheres encontra-se em situações estruturalmente mais precárias e vulneráveis que os homens, dada às diferenças nas normas de inserção da mulher no mercado de trabalho.

Outro aspecto importante investigado foi a dinâmica migratória da população do bairro. Constatou-se que $60 \%$ residiam entre dez e quinze anos no bairro. No entanto, a permanência em longo prazo em uma área sem saneamento básico é uma situação de risco constante. À medida que esse tempo aumenta, há uma tendência em aumentar significativamente a situação de risco do indivíduo.

Constatou-se que apenas $5 \%$ de indivíduos possuíam idade inferior a 20 anos e $8 \%$ idade superior a 50 anos. A partir desses resultados, infere-se que a condição de vida expressa pelas crianças e idosos passa a depender de práticas alimentares, renda familiar, assistência básica à saúde e o grau de exposição de crianças à ambientes insalubres, haja visto o baixo número de indivíduos com idade inferior a 20 anos.

Em todos os domicílios estudados a renda per capita foi inferior a três salários mínimos, revelando o baixo poder aquisitivo das famílias. Além disso, foi possível constatar que muitas famílias sobrevivem com renda inferior por não possuírem emprego fixo. A baixa renda pode ainda estar diretamente relacionada a baixos níveis de escolaridade dos moradores do bairro São Benedito. Em geral, os sujeitos da pesquisa sobrevivem do comércio informal, realizando atividades como ambulantes, pedreiros, pintores, catadores de material reciclável, faxineira, vendedores de frutas e verduras. Apenas $18 \%$ dos entrevistados estão inseridos no mercado formal de trabalho e são detentores de três ou mais salários mínimos. No entanto, o efeito colateral da baixa escolarização pode ter aproximado esses moradores do trabalho precarizado, cuja necessidade de ajudar a família tornou-se fator central para a busca de qualquer atividade, já que grande parte desses indivíduos não possui o Ensino Fundamental completo.

Quanto às características das moradias, constatou-se que 75\% dos domicílios visitados são de alvenaria. Contudo, a maioria deles encontra-se em condições muito precárias. Em 96\% dos domicílios não há filtro de água para consumo, nem qualquer outro aparelho para filtrar ou purificar a água. No discurso dos moradores entrevistados fica nítido que para eles o poder público municipal é o único responsável por oferecer e manter a qualidade da água aos moradores, tornando-a própria ao consumo. É possível que a falta de filtros nos domicílios possa 
estar relacionada com desconhecimento ou desvalorização da população sobre a importância do mesmo para a manutenção/promoção da saúde. Por outro lado, a baixa renda das famílias, aliada a outras prioridades, como a própria alimentação diária, podem explicar a ausência de filtros residenciais.

No que tange ao esgotamento sanitário, tido como o conjunto de obras destinadas para coleta, tratamento e disposição final das águas residuárias (Philippi Jr. \& Malheiros, 2005), verificou-se no bairro estudado a falta de investimentos nesse setor. Menos da metade das residências visitadas são beneficiadas por serviços de saneamento básico, as quais acabam por despejar seus dejetos nos mananciais, poluindo o lençol freático, rios e lagoas da região.

Em relação ao lixo, também se observou uma situação muito desfavorável. Muitos resíduos dispostos irregularmente foram evidenciados, revelando mais um problema ambiental de amplitude complexa. Sobre esse aspecto, salienta-se que a destinação final do lixo lançado no rio, por exemplo, constitui um grave problema ambiental, pois, além do perigo de contaminar suas águas, podem acarretar doenças à população (Rodrigues \& Malafaia, 2009).

Outro quesito investigado diz respeito à frequência de visitação de agentes de saúde e da vigilância sanitária no bairro que, conforme Silva \& Dalmaso (2002) é a mola propulsora para a consolidação do Sistema Único de Saúde (SUS), a organização das comunidades e a prática regionalizada e hierarquizada de assistência, na estruturação dos distritos sanitários. Dos entrevistados, $70 \%$ afirmaram que os agentes de saúde e da vigilância sanitária visitam os domicílios apenas uma vez por mês e 30\% afirmaram que nunca foram visitados pela vigilância sanitária e/ou pelos agentes de saúde. Em muitas falas observou-se nos moradores certa revolta em relação não apenas à ausência dessas visitas, as quais eles consideram importantes, como também em relação a providências não tomadas após a constatação de problemas diversos identificados no bairro pelos próprios agentes.

Segundo Scotney (1981), a visita domiciliar tem como finalidade levantar dados sobre condições de habitação e saneamento, avaliar as condições ambientais e físicas em que vive o indivíduo e sua família, aplicar medidas de controle nas doenças transmissíveis ou parasitárias. Tais visitas são importantes para alertar e ressaltar a importância do saneamento básico para que possa haver ações de prevenção dos efeitos de determinados procedimentos sobre o meio ambiente de forma a manter, preservar e assim, melhorar as condições de qualidade de vida da população da comunidade, inclusive do próprio ambiente social. Entretanto, caso essas visitas não ocorram periodicamente ou não estejam ocorrendo (conforme relatado por alguns moradores), os seus propósitos não são alcançados e a população destaca-se como a mais prejudicada.

Outro aspecto apontado pela pesquisa relaciona-se às doenças de veiculação hídrica. Quando questionados sobre a ocorrência de verminoses ou protozoonoses, verificou-se que $16,7 \%$ dos entrevistados tiveram ascaridíase; $13,4 \%$ enterobiose; $6,7 \%$ ancilostomíase; 4,4\% giardíase e $20 \%$ outros casos. Contudo, a freqüência de verminoses e outras doenças veiculadas pela água pode ser muito maior, uma vez que em alguns casos os moradores podem conviver com a doença sem diagnosticá-la. Esses dados corroboram estudos que mostram a necessidade de maior atenção para os impactos da degradação dos recursos hídricos e a saúde humana, haja visto que, uma vez preservados e conservados, muitos casos de doenças podem ser evitados. Conforme discutido por Rodrigues \& Malafaia (2009), os recursos hídricos (quando poluídos, sobretudo, por esgotos domésticos) compreendem veículos de várias enfermidades, as quais 
apresentam agentes etiológicos que possuem um ciclo de vida de alguma forma ligado com tais recursos, seja na forma de águas estagnadas, rios, represas, estuários ou lagos. De acordo com dados da UNESCO (1999), estima-se que mundialmente morrem cerca de 34 mil pessoas/dia em decorrência de doenças relacionadas aos recursos hídricos. Já no Brasil, 65\% das internações hospitalares devem-se a doenças veiculadas pela água. Conforme exposto por Guerrant et al. (1996), as doenças de veiculação hídrica em continentes como América Latina, África e no sudoeste da Ásia matam mais pessoas que todas as outras doenças em conjunto.

Por outro lado, podemos dizer que o quadro observado em bairros como o investigado neste estudo, nos quais se evidenciam precárias condições de moradia, baixo nível de escolaridade e fracas condições de saneamento básico, culminam também em problemas relacionados a questões sociais. Além disso, há que se ressaltar, conforme discutido por Takayanagui (2005), que comumente evidencia-se uma maior incidência de doenças relacionadas à água, em geral, quando contabilizadas em um contexto em que as famílias vivenciam outras condições inadequadas, como a falta de alimentação, a pobreza, a ignorância, dentre outras, o que acaba por resultar em uma situação biológica, social e cultural ainda mais desfavorável à população.

No bairro investigado fica evidente que a má condição de saúde dos habitantes, reconhecida por muitos dos próprios entrevistados, está associada ingestão de água não tratada na maioria das residências, ao lixo produzido e dispostos de forma inadequada, bem como às condições precárias de higiene e de saneamento básico. O controle da qualidade da água utilizada para o consumo humano, bem como a coleta de lixo, a forma de acondicionamento e seu destino final adequado podem, por exemplo, assegurar a redução e o controle de diversas doenças, como hepatite, dengue, diarréias, cólera, além de uma série de verminoses.

Em relação aos resíduos no bairro investigado, constatou-se irregularidades ligadas ao tratamento dos mesmos, o que contraria a legislação ambiental. Quando indagados sobre a existência de um aterro sanitário no município, $70 \%$ dos sujeitos entrevistados afirmaram que o mesmo não existe; $20,3 \%$ afirmaram que nunca observaram e $6,7 \%$ dos pesquisados disseram não ter conhecimento do local destinado aos resíduos coletados. Dessa forma, o desconhecimento da população pode indicar que os resíduos sólidos urbanos estão sendo destinados de forma inadequada, ou seja, expostos em terreno a céu aberto, sem responsabilidade sobre os riscos advindos dessa prática.

De acordo com Philippi-Jr \& Aguiar (2005), os aterros sanitários, ao contrário dos lixões, são os locais correto de destino para os resíduos urbanos produzidos. Tais locais são obras de engenharia destinadas a acomodar os resíduos sobre o solo, minimizando os impactos ambientais e os riscos à saúde humana. Entre as soluções sanitárias e ambientalmente adequadas, os aterros sanitários são considerados as formas mais baratas para solucionar a questão dos resíduos sólidos domésticos.

O presente estudo também investigou se os sujeitos eram capazes de perceber a poluição evidente do rio que corta o bairro. Dos entrevistados, $73,3 \%$ não consideram a poluição das águas como fator preocupante; $20 \%$ consideram o rio poluído e $6,7 \%$ dos entrevistados não souberam opinar. Esses dados podem estar ligados ao distanciamento do indivíduo para com as questões ambientais. A convivência cotidiana com determinados problemas ambientais (como a poluição do rio que corta o bairro), sem o despertar para a problematização, pode não preocupar os moradores. 
Outro aspecto interessante observado no presente estudo diz respeito ao baixo percentual de indivíduos $(26,7 \%)$ dispostos a participar da solução dos problemas evidenciados no bairro, incluindo a adoção de práticas de redução de consumo de água nas residências. Esses dados revelam, entre outros aspectos, a necessidade veemente de desenvolvimento de ações no bairro voltadas ao aumento do interesse dos moradores para com os assuntos relacionados à temática ambiental. Nesse contexto, certamente abordagens relacionadas à Educação Ambiental (EA) formal e informal são estratégias interessantes que podem não apenas ajudar na resolução dos problemas identificados, mas também induzir dinâmicas sociais, de início na comunidade local e, posteriormente, em redes mais amplas de solidariedade, promovendo a abordagem colaborativa e crítica das realidades socioambientais e uma compreensão autônoma e criativa dos problemas que se apresentam e das soluções possíveis para eles (Sauvé, 2005).

No presente estudo também foi apurado quais ações o poder público municipal deveria executar na busca de alternativas para minimizar a questão ambiental e promover à proteção do meio ambiente, na opinião dos moradores. Apesar da importância do serviço de saneamento básico para o meio ambiente, este foi um dos índices que tiveram menor frequência na opinião dos entrevistados, uma vez que $28 \%$ disseram que o prefeito deveria plantar árvores. Mesmo os moradores convivendo com a realidade do esgoto a céu aberto na porta da casa, $50 \%$ dos entrevistados não souberam apontar nenhuma ação a ser realizada. Eles parecem habituados com a poluição e não veem a degradação ambiental como problema. É possível que tenha ocorrido habituação e resignação às condições extremas de vida e apreenderam o fenômeno como um elemento normal de sua própria condição humana.

\section{CONSIDERAÇÕES FINAIS}

Com base no que foi exposto, destaca-se que as precárias condições de saneamento, saúde e educação enfrentadas no bairro podem estar ligadas a um aparente desconhecimento da população, a qual ignora a gravidade dos problemas, tornando-se vítimas da violação dos direitos sociais mais básicos à vida. 0 fato de a maioria da população desconhecer os problemas ambientais, por exemplo, é considerado preocupante, pois são questões que agravam diretamente a qualidade de vida dos habitantes, e que podem contribuir para um processo ainda maior de degradação ambiental local e de saúde pública. A falta de informação leva à incompreensão de problemas, o que aumenta as chances dos moradores estagnarem na condição sócio-ambiental, reduzindo as chances de melhorias na qualidade de vida.

Diante desse cenário de vulnerabilidade vivenciada pelas famílias que sofrem com a precariedade e insalubridade das suas moradias, torna-se fundamental a intervenção do assistente social, tendo em vista que este profissional busca intervir nas expressões da questão social de forma transformadora, criando respostas profissionais sustentáveis, planejando e sistematizando suas ações no campo das mobilidades e possibilidades para que estes sujeitos tenham autonomia e emancipação.

Por fim, pode-se dizer que este estudo retrata uma condição socioambiental merecedora de atenção e necessitada do desenvolvimento de ações que sejam conduzidas no sentido de melhorar a qualidade de vida da população. Em outras palavras, a institucionalização de políticas públicas locais é urgente. 


\section{REFERÊNCIAS BIBLIOGRÁFICAS}

1. AMÊNDOLA, J. Sales - Sua Origem e Evolução. 1 ed. Ribeirão Preto SP: Villimpress, 1999.

2. BUCCHERI-FILHO, A.T. Qualidade ambiental no bairro Alto da XV, Curitiba/PR. 92 f. (Dissertação de Mestrado). Universidade Federal do Paraná, Curitiba, 2006.

3. FIRMINO, P.F.; MALAFAIA, G.; RODRIGUES, A.S.L. Diagnóstico da integridade ambiental de trechos de rios localizados no municípios de Ipameri, sudeste do Estado de Goiás, através de um protocolo de avaliação rápida. Brazilian Journal of Aquatic Science and Technology, v. 15, n. 2, p. 1-12, 2011.

4. FLECK, A.C.; WAGNER, A. A mulher como a principal provedora do sustento econômico familiar. Psicologia em Estudo, v. 8, n. Esp., p. 31-38, 2003.

5. GIATTI, L.L.; ROCHA, A.A.; SANTOS, F.A.; BITENCOURT, S.C.; PIERONI, S.R.M. Basic sanitary conditions in Iporanga, São Paulo State, Brazil. Revista de Saúde Pública, v. 38, n. 4, p. 1-6, 2004.

6. GÜNTHER, W.M.R.. Poluição do Solo. In: PHILIPPI Jr., Arlindo; PELICIONI, Maria Cecília Focesi, (Ed.). Educação Ambiental e Sustentabilidade. Barueri SP: Manole, 2005. p. 195-215.

7. GUERRANT, R.L.; SOUZA, M.A.; NATIONS, M.K. At the edge of development: health crisis in a transitional society. Carolina: Academic Press, 1996.

8. INSTITUTO BRASILEIRO DE GEOGRAFIA E ESTATístiCA (IBGE). Censo 2010. Disponível em: http://www.ibge.gov.br/home/estatistica/populacao/censo2010/calendario.shtm. Acesso em 10 de janeiro de 2012.

9. LIPOVETSKY, G. A terceira mulher. São Paulo: Companhia das Letras, 2000.

10. MENDONÇA, F. Aspectos da problemática ambiental urbana da cidade de Curitiba/PR e o mito da "Capital Ecológica". GEOUSP - Espaço e Tempo, n. 2, p. 1-8, 2002.

11. NATAL, D. et al. Epidemiologia Aplicada à Educação Ambiental. In: PHILIPPI Jr., A.; PELICIONI, M.C.F. (Eds.). Educação Ambiental e Sustentabilidade. Barueri SP: Manole, 2005. p. 85-134.

12. ORGANIZAÇÃO DAS NAÇÕES UNIDAS PARA A EDUCAÇÃO, CIÊNCIA E CULTURA (UNESCO). What price water? The Unesco Courier, v. 2, p. 17-27, 1999.

13. PERUCCHI, J.; BEIRÃO, A.M. Novos arranjos familiares: paternidade, parentalidade e relações de gênero sob o olhar de mulheres chefes da família. Psicologia Clínica, v. 19, n. 2, p. 57-69, 2007.

14. PHILIPPI JÚNIOR, A.; AGUIAR, A.O. Resíduos sólidos: características e gerenciamento. In: PHILIPPI JÚNIOR, A. (Org.). Saneamento saúde e meio ambiente, 2005.

15. PHILIPPI Jr, A. MALHEIROS, T. F. Saúde Ambiental e Desenvolvimento. São Paulo: Manole, 2005.

16. PREFEITURA MUNICIPAL DE SALES. Vista aérea de Sales, SP. Disponível em: http://www.sales.sp.gov.br/vista_aerea/Vista_Aérea/index.htm. Acesso em 26 de março de 2012.

17. RODRIGUES, A.S.L.; MALAFAIA, G. Degradação dos recursos hídricos e saúde humana: uma atualização. Revista Saúde e Ambiente, v. 10, n. 1, p. 13-23, 2009. 
18. RODRIGUES, A.S.L.; RESENDE-NETO, O.A.; MALAFAIA, G. Análise da percepção sobre a problemática relativa aos resíduos sólidos urbanos revelada por moradores de Urutaí, Goiás, Brasil. Enciclopédia Biosfera, v. 6, n. 11, p. 1-10, 2010.

19. ROSA, M.; SILVA, L.A.A. Desastres naturais ou negligência humana? Disponível em: http://www.observatoriodasmetropoles.ufrj.br/artigo_boletim-017.htm. Acesso em 20 de fevereiro de 2012.

20. SAUVÉ, L. Uma cartografia das correntes em educação ambiental. In: SATO, M.; CARVALHO, I.C.M. (Orgs.). Educação Ambiental: pesquisas e desafios. Porto Alegre: Artmed, 2005.

21. SCOTNEY, N. Educação para a saúde. São Paulo, Paulinas, 1981.

22. SILVA, J.A.; DALMASO, W. Agente comunitário de saúde: o ser, o saber, o fazer. Rio de Janeiro: Editora Fiocruz, 2002.

23. TAKAYANAGUI, Ângela Maria Magosso. Gerenciamento de Resíduos de Serviços de Saúde.In: PHILIPPI Jr., Arlindo (Ed.). Saneamento, Saúde e Ambiente: Fundamentos para um desenvolvimento sustentável. Barueri SP: Manole, 2005. p. 323-374.

24. VIEIRA, E.A. A questão ambiental do resíduo/lixo em Ribeirão Preto (SP). 170 f. (Dissertação de Mestrado). Universidade Estadual Paulista - Campus de Rio Claro, Rio Claro, 2002. 